\title{
Teachers' And Students' Perceptions Of Students' Problem-Solving Difficulties In Physics: Implications For Remediation
}

\author{
Ayodele O. Ogunleye, University of Lagos, Nigeria
}

\begin{abstract}
In recent times, science education researchers have identified a lot of instruments for evaluating conceptual understanding as well as students' attitudes and beliefs about physics; unfortunately however, there are no broad based evaluation instruments in the field of problem-solving in physics. This missing tool is an indication of the complexity of the field. However, one obvious way by means of which we can evaluate students' problem-solving skills is to find out how teachers and students perceive problem-solving difficulties in physics. Using a population of 210 Senior Secondary School (SSS) physics students and their teachers, this study investigated aspects of students' problem-solving difficulties in physics and possible remedies. The result of the analysis show that lack of students understanding of the problem and their poor mathematical skills constitute the major obstacles in the circle of difficulties that students experience in solving physics problems. Furthermore, the study identified two major remedies that could possibly assist students in solving physics problems: 1) the provision of enough home assignments and 2) the employment of qualified physics teachers. The results are further discussed in terms of their implications for effective learning of physics.
\end{abstract}

Keywords: Problem-solving, evaluation, home assignment, qualified physics teachers, mathematical skills.

\section{INTRODUCTION}

cience has been and will continue to be of tremendous importance to humanity for its ability to explain many of the everyday occurrences in life, as well as playing a very significant role in the technological development of both developing and developed nations of the world. In performing these roles, science apparently depends on the language of mathematics as a means of communicating its quantitative and qualitative aspects. Some science educators, for example Abdullah (1982), stressed the need to use mathematics in science because the services of the former to the latter are becoming indispensable.

Physics, being the most fundamental science, derives its reputation as a difficult subject primarily from its dominant problem-solving nature. Furthermore, as a subject that deals with physical quantities and mathematical exactitudes, virtually all branches of physics are concerned with problem-solving.

A number of authors have offered various definitions of problem solving. Ausubel (1971) defined problem solving as a form of discovery learning, bridging the gap between the learners existing knowledge and the solution of the problem, while Gagne (1970) viewed problem solving as the result of assembling rules already known to create a new superior rule which is learned and allows solution of the problem. According to Watts (1994), a problem is "a challenge, a situation without solution that cannot be resolved immediately. Problem solving can also be viewed as a cognitive processing directed at achieving a goal when no solution is obvious to the problem solver (Meyer, 1992) From these definitions, one can say that for an individual to be able to solve a problem, he or she must possess the relevant information necessary to solve the problem and thereafter should be able to reason with such information in order to be able to solve the problem. In other words, the individual should read the problem carefully and try to understand it. He should be able to identify the physical laws, principles, and equations involved 
in the problem and make a graph, sketch, or drawing to visualize the situation described in the problem. Finally, he should be able to list all quantities involved in the problem and assign symbols to them.

Problem-solving has become one of the most important valued areas of investigation in science education, particularly physics and chemistry (Gabel, 1994). Unfortunately, research studies have found that many students perform algorithmic or mathematical manipulation by rote memorization of formulae without having a basic understanding of specific concepts (Nakhleh, 1993). The reasons why students find problem-solving difficult have been identified by many researchers as students' failure to construct meanings from the problem statement, not being able to link the meaning of the problem to their knowledge structures, or simply lacking the appropriate knowledge structure for that specific content area (Nakleh, 1993). The basis for a great deal of research in solving problems can be found in the works of Polya (1957), who identified a four-stage model for problem-solving. These are recall, planning, implementation and evaluation. Frazer et al (1979) proposed a similar four-stage model consisting of defining the problem, selecting the appropriate information, combining the separate pieces of information and evaluation. Other relevant studies include those of Greeno's (1973) five-state model starting with reading the text, interpreting the concepts, retrieving relevant information from long-term memory, constructing a solution plan, and carrying out the operations required to solve the problem. Schoenfeld (1992) followed up the research work of Polya when he distinguished between five cylindrical episodes of solving problems: 1) survey the problem, 2) activate knowledge, 3) make a plan, 4) carry out the plan, and 5) check the answer. Stewart \& Rudolph (2001), after considering the nature of scientific problems, identified two important types of problems: Model-Data Fit Problems, in which solvers fit available data into an appropriate explanatory model and Conceptual Problems, where solvers must check the conceptual coherence of their explanatory model.

\section{THE PROBLEM}

Even though a number of researches had been carried out to find reasons why students fail to solve problems, most of these investigations are general and outside the field of physics. In addition, many such investigations did not consider the opinions of teachers and students as to why they find physics problems difficult to solve. This study, therefore, attempts to investigate physics students' and teachers' perceptions on students' inability to solve physics problems. By comparing these, it is hoped that a model might evolve which could serve as an instrument for physics teaching and learning, as well as a basis for further research in the field of physics education.

Specifically therefore, this study sought to investigate physics teachers' and students' opinions on:

1. the reasons for students' inability to solve problems

2. the corrective measures needed to overcome these difficulties

\section{METHODOLOGY}

A Likert-type 5-point scale attitude questionnaire was constructed. The content of the questionnaire was drawn out from an analysis of a preliminary interview field with 50 secondary school physics students in which every student was asked to state his difficulties. Five physics educator experts decided on the comprehensiveness and they all agreed that the items adequately covered the primary science content; and they then validated the questionnaire. The instrument was later pilot - tested. Its internal validity was established by using the spilt-half technique, whereby scores on two equivalent halves of the instrument were totalled separately and the correlation coefficient calculated, whose value was later corrected by using the Spearman Brown Prophecy formula. The corrected co-efficient value was 0.92 . The questionnaire was later administered to 210 senior secondary school physics students and 16 physics teachers. The need to involve students lies in the fact that, giving them the opportunity to express their own opinions about their own difficulties and suggest possible remedies, by doing so, one should be able to get to the root of where the problem lies. Kahn (1973) once noted "any research on learning and teaching that fails to take into account the feelings, reactions and opinions of pupils is not worthwhile". The involvement of physics teachers would enable one to collect a rich source of information about students' difficulties in problem-solving. 
The questionnaire contained three sections designed for two types of respondents; i.e. physics students and their physics teachers. Section A sought general nature information from the respondents, such as their sex, school, etc. Section B presented a list of ten items as to the reasons for students' difficulties in solving physics problems, two of which were:

1. the inability of students to remember the necessary equations

2. the lack of good textbooks on problem-solving in physics

Section $\mathrm{C}$ contained ten items of suggestions aimed at reducing these difficulties, two of which were:

1. providing enough assignments and revision of past question papers

2. providing good physics textbooks

\section{RESULTS AND DISCUSSION}

Ten possible reasons were stated as to why students fail to solve physics problems. Physics teachers and their students were to make their choices from the five possible options provided. Table 1 shows the pooled frequency response categories and the Index of Agreement for each item.

Table 1: Pooled Frequency Categories and Index of Agreement of Physics Students and their Teachers on the Reasons for Students Difficulties in Solving Physics Problems

\begin{tabular}{|l|l|c|c|c|c|c|c|}
\hline \multicolumn{1}{|c|}{ STATEMENT } & SA & A & UN & DA & SD & $\begin{array}{c}\text { INDEX OF } \\
\text { AGREEMENT }\end{array}$ \\
\hline 1. & $\begin{array}{l}\text { Insufficient laboratory practical work in the } \\
\text { topic area. }\end{array}$ & 74 & 42 & 38 & 29 & 23 & 0.63 \\
\hline 2. & $\begin{array}{l}\text { Inability to remember the necessary } \\
\text { equations to solve the problem }\end{array}$ & 68 & 77 & 33 & 16 & 13 & 0.70 \\
\hline 3. & Lack of understanding of the problem & 98 & 71 & 21 & 12 & 5 & 0.78 \\
\hline 4. & $\begin{array}{l}\text { Not having enough practice in problem- } \\
\text { solving in class }\end{array}$ & 104 & 59 & 22 & 14 & 7 & 0.78 \\
\hline 5. & $\begin{array}{l}\text { Students poor understanding of the necessary } \\
\text { mathematical skills }\end{array}$ & 89 & 82 & 16 & 14 & 6 & 0.78 \\
\hline 6. & $\begin{array}{l}\text { Poor understanding of the physics } \\
\text { definitions, principles and rules involve. }\end{array}$ & 73 & 74 & 19 & 26 & 15 & 0.70 \\
\hline 7. & $\begin{array}{l}\text { Poor teaching and lack of motivation from } \\
\text { the teacher. }\end{array}$ & 83 & 51 & 26 & 26 & 20 & 0.68 \\
\hline 8. & $\begin{array}{l}\text { Insufficient home assignments or exercises } \\
\text { on physics problems. }\end{array}$ & 68 & 70 & 33 & 17 & 19 & 0.68 \\
\hline 9. & $\begin{array}{l}\text { Confusion arising from units and their } \\
\text { conversions. }\end{array}$ & 48 & 77 & 40 & 27 & 15 & 0.63 \\
\hline 10. & $\begin{array}{l}\text { Lack of good textbooks or course materials } \\
\text { on physics problems. }\end{array}$ & 48 & 51 & 30 & 37 & 41 & 0.53 \\
\hline
\end{tabular}

SA - Strongly Agree, A - Agree, DA - Disagree, SD - Strongly Disagree, UN - Undecided

From Table 1, the order of the index of agreement of students' inability to solve problems is as follows:

1. Lack of understanding of the problem.

2. Not having enough practice in problem-solving in class.

3. Students' poor understanding of the necessary mathematical skills.

4. Poor understanding of the physics definitions, principles and rules involved.

5. Inability to remember the necessary mathematical skills.

6. Lack of motivation from the teacher.

7. Insufficient home assignments or exercises on physics problems.

8. Insufficient laboratory practical work in the topic area. 
9. Confusion arising from units and their conversions.

10. Lack of good textbooks or course materials on physics problems.

The reasons were further subdivided into three categories as follows:

$$
\begin{array}{ll}
\text { General reasons include: } \\
\circ \quad \text { Insufficient laboratory practical work in the topic area. } \\
\circ & \text { Confusion arising from units. } \\
& \text { Lack of good physics textbooks. }
\end{array}
$$

Of the three items in this area, the most important is laboratory work in physics, with an index of agreement of 0.63 . This confirms the importance of laboratory work in promoting skills necessary to solve problems. Teachers should therefore provide as many laboratory experiments in any topic area, even if it requires designing new experiments. On the attention given to units, the index of agreement is also 0.63 . This aspect is equally important as many students still experience difficulties with units and their conversions. Finally, the issue of lack of textbooks is rated lowest of all, which possibly confirms the availability of more than enough physics textbooks in the market.

$$
\begin{array}{ll}
\text { Specific reasons related to skills necessary for solving problems include: } \\
\circ \quad \text { Lack of understanding of the problem. } \\
\circ & \text { Poor understanding of physics definitions, principles and rules involved. } \\
\circ & \text { Inability to remember the necessary equations. } \\
\circ & \text { Students' poor understanding of the necessary mathematical skills. }
\end{array}
$$

The specific reasons adduced here are closely aligned to the stages of problem-solving discussed earlier. The index of agreement for each of the items is shown in Table 1.

It is important to note that all of the items in this section have a very high index of agreement rate. Thus, a student who does not understand the problem cannot, in fact, proceed to solving the problem, which is stage one of problem-solving. This difficulty is further compounded in all other stages and attains a highest rate on stage four where the inability of students to display basic mathematical skills is ranked highest in the index of agreement. It is important, therefore, that in solving physics problems, students should be encouraged to look for concept relatedness in the problem; thereafter, they should attempt to break the problem into what Frazer et al (1982) calls "subproblems", which could be solved systematically while moving toward the overall solution.

(c) Methods that relate to the techniques used in solving problems include:

$0 \quad$ Not having enough practice in problem-solving.

- Insufficient home assignments or exercises on physics problems.

- Poor teaching and lack of motivation from the teacher.

Items that fall into this category also have a high index of agreement, with the highest being "not having enough practice in problem-solving in class" $(0.78)$ then "poor teaching and lack of motivation from teachers" (0.68), and finally "insufficient home assignments or exercises in physics" (0.68). It is important to note that the issue of methodology is so vital to pupils' overall achievement in science. Research studies on classroom interactions have shown inadequate teaching carried out by teachers in science classrooms; hence, rote memorization of facts and principles dominate the learning styles used by many students. This gives a general picture of teaching and learning situations as they exist in our classrooms that are now evidence of this result.

\section{SUGGESTIONS FOR IMPROVING STUDENTS PERFORMANCES IN PROBLEM-SOLVING}

Ten possible items were suggested as ways to reduce students' difficulties in problem-solving. Physics students and their teachers were to choose from the five possible options given. Table 2 shows the pooled frequency response categories and the index of agreement for each item as follows:

1. Providing enough home assignments and past examination question papers. 
2. $\quad$ Employing qualified and experienced teachers to teach physics.

3. Preparing a detailed plan or review notes on how to solve problems.

4. $\quad$ Explaining equations to be used in solving problems.

5. More laboratory work in physics should be performed.

6. Provision of good textbooks that give more examples on problem-solving

7. Arranging or organizing tutorial and small group problem-solving periods whereby able students can teach the less able ones how to solve problems.

8. Teaching units and their conversion each time a problem is to be solved.

9. Repeating lessons on physics topics already taught.

10. Repeating lessons already taught in mathematics during previous years in physics lessons.

Table 2: Pooled Frequency Response Categories and Index of Agreement of Physics Students and their Teachers on the Suggestions offered for Improving Students Problem-Solving Skills

\begin{tabular}{|l|l|c|c|c|c|c|c|}
\hline \multicolumn{1}{|c|}{ STATEMENT } & SA & A & UN & DA & SD & OF AGREEMENT \\
\hline 1. & $\begin{array}{l}\text { More laboratory work in physics should be } \\
\text { performed. }\end{array}$ & 112 & 61 & 18 & 10 & 6 & 0.80 \\
\hline 2. & $\begin{array}{l}\text { Explaining the equations to be used in } \\
\text { solving physics problems. }\end{array}$ & 103 & 86 & 13 & 3 & 1 & 0.83 \\
\hline 3. & $\begin{array}{l}\text { Preparing a detailed plan or review notes } \\
\text { on how to solve problems. }\end{array}$ & 107 & 72 & 23 & 3 & 2 & 0.83 \\
\hline 4. & $\begin{array}{l}\text { Arranging or organizing tutorial and small } \\
\text { group problem-solving periods whereby } \\
\text { able students can teach the less able ones } \\
\text { on how to solve problems. }\end{array}$ & 95 & 67 & 23 & 13 & 9 & 0.78 \\
\hline 5. & $\begin{array}{l}\text { Repeating lessons already taught in } \\
\text { mathematics during previous years in } \\
\text { physics lessons. }\end{array}$ & 29 & 59 & 37 & 56 & 27 & 0.50 \\
\hline 6. & $\begin{array}{l}\text { Repeating lessons on physics topics } \\
\text { already taught. }\end{array}$ & 46 & 60 & 35 & 45 & 21 & 0.58 \\
\hline 7. & $\begin{array}{l}\text { Employing qualified and experienced } \\
\text { teachers to teach physics. }\end{array}$ & 135 & 50 & 11 & 4 & 7 & \\
\hline 8. & $\begin{array}{l}\text { Providing enough home assignments and } \\
\text { past examination question papers. }\end{array}$ & 123 & 58 & 9 & 10 & 6 & 0.58 \\
\hline 9. & $\begin{array}{l}\text { Teaching units and their conversion each } \\
\text { time a problem is to be solved. }\end{array}$ & 65 & 81 & 34 & 21 & 6 & 1.05 \\
\hline 10. & $\begin{array}{l}\text { Provision of good textbooks that give more } \\
\text { examples on problem-solving. }\end{array}$ & 108 & 67 & 17 & 6 & 9 & 0.70 \\
\hline SA
\end{tabular}

SA - Strongly Agree, A - Agree, DA - Disagree, SD - Strongly Disagree, UN - Undecided

The analysis of the results in Table 2 shows that the highest index of 1.05 was obtained for the statement, "providing home assignments and past examination question papers". The reason for this might be the phrase "examination question papers". This is closely followed by the suggestion "employing qualified and experienced teachers to teach physics". It is important to note that this particular suggestion remains a problem in Nigeria today. For example, a quick observation of teachers' qualifications shows that a greater percentage of teachers who teach physics in our schools are non-physics majors. The reasons for students' inability to solve physics problems, therefore, cannot be far-fetched.

On the suggestion of preparing a detailed plan or review notes on how to solve problems, it is important to highlight that problem-solving starts with a students' identification and understanding of the issue in question. Their skills will depend on their knowledge of the content, as well as the way the problem is linguistically posed; hence, there is the need for a detailed plan on how to solve problems or students should be given detailed steps and procedures to be followed when solving any problem. 
The fourth suggestion deals with explaining equations to be used in solving problems. This is quite important as physics is extremely expressed in formulae, and it is important for a student to be able to understand and recall the appropriate equations to be used in solving a physics problem.

Another suggestion that is equally worth discussing has to do with teaching units and their conversion. It is important to note that units play a significant role in the computation of problems in physics. Many errors could be obtained using wrong units; hence, students should be properly taught units and their conversions.

\section{CONCLUSION}

This study sought physics students and their teachers' opinions on difficulties encountered in solving physics problems and possible remedies. One can say that there is a general agreement between physics teachers and their students in these two areas. The high failure rate in physics in externally conducted examinations in Nigeria could, in part, be attributed to these difficulties encountered by students in problem-solving, which is reflected in their inability to understand the subject matter content and as a result of general lack of guidelines given to students on how to solve physics problems. It is therefore recommended that students should be given the opportunity of having regular problem-solving sessions during the process of learning physics. Curriculum developers and science educators might also need to incorporate mathematical concepts that are useful and necessary to the understanding of physics in new physics curriculum and textbooks. It is important to note that a few specific skills might be necessary to solve one type of problem but not another problem, even though the strengths and weaknesses of a particular student remain the same, regardless of the environment. The results of this study are, in fact, consistent with other research studies on problem-solving.

\section{AUTHOR INFORMATION}

Dr. Ayodele O. Ogunleye is a teacher and science educator by profession. He is currently a Senior Lecturer in Science Education at the Faculty of Education, University of Lagos, Nigeria. He has a passion for teaching and research, especially in physics education. He obtained M.Sc. in Theoretical Physics from Friendship University in Moscow; M. Ed in Science Education from Chelsea College of Science and Technology, University of London; M. $\mathrm{Sc}$ in Computing and IT from University of Lagos, Nigeria. In addition, he earned a Diploma in Science Education from Chelsea College of Science and Technology, University of London.

\section{REFERENCES}

1. Abdulahi, A. (1982) Science Teaching in Nigeria. Ilorin: Atoto Press,

2. Ausubel, D. P. (1971) The Psychology of Meaningful Learning. New York: Grune and Stratton.

3. Fenshaw, J. B. and Butt, L. W. (1984) "Prior Knowledge and the Learning of Science". Studies in Science Education 1, pp 61-81.

4. Frazer, J. B. and Butt, L. W. (1982) "Relationship between perceived levels of classroom individualization and science related attitudes". Journal of Research in Science Teaching 19, 2, pp 143 - 154.

5. Gagne, R. M. (1966) "Human Problem-Solving Internal and External Events". In Kleinmuntz B. (Ed.) Problem-Solving Research Methods and Theory. New York, John Willey.

6. Gagne, R. M. (1970) The Conditions of Learning. (2d Ed). New York: Holt, Rinehart and Winston.

7. Greeno, J. G. (1973) The Structure of Memory and the Process of Solving Problems in Solsol R. (Ed) Contemporary Issues in Cognitive Psychology. The Lagola Symposium, Washington D. C.

8. Maloney, D. P. (1993) Research on problem-solving in Physics. In D. L. Gabel (Ed) Handbook of Research on Science Teaching and Learning. Toronto, Macmillan

9. Meyer, R. E. (1992) Thinking problem-solving, cognition, New York: Freeman

10. Polya, G. (1975) How to solve it, New York: Double Day and Co., Inc.

11. Schoenfeld, A. H. (1992). Learning to think mathematically: Problem-solving, meta-cognition and sense making in mathematics. In D. A. Grouws (eds). Handbook of research in Mathematics teaching (New York: McMillan Publishing), 334-370.

12. Stewart, J., \& Rudolph, J. (2001). Considering the nature of scientific problems when designing science curriculum. Science Education, 85, 207-222. 